\title{
Dye Decolourization using Fungal Laccase: A Review
}

\author{
Vidya S \\ Department of Biotechnology \& Biochemical Engineering \\ Sree Buddha College of Engineering, Alappuzha, Kerala, India \\ Chinchu Chandran \\ Department of Biotechnology \& Biochemical Engineering \\ Sree Buddha College of Engineering, Alappuzha, Kerala, India \\ Meera Bai S \\ Department of Biotechnology \& Biochemical Engineering \\ Sree Buddha College of Engineering, Alappuzha, Kerala, India
}

\begin{abstract}
Laccases are multi-copper oxidases, found in many plants, fungi and microorganisms. It was found that laccase plays a crucial role in the formation of lignin by promoting the oxidative coupling of monolignols, a family of naturally occurring phenols. The isolation and identification of laccase from white rot fungi plays a vital role in exploiting its environmental and biotechnological application. The increased use of a wide varieties of synthetic dyes in different industries has raised a hazardous environmental aware. Researchers found that $\mathbf{1 7 - 2 0 \%}$ of fresh water pollutions are caused by the presence of these dyes. Dyes are the most difficult constituents to remove by conventional waste water treatment, and are mainly removed by physical and chemical methods, which are expensive. Hence the biological processes become the most prominent technology for dye decolourisation. Laccase based decolourization treatment are highly advantageous to bioremediation technologies. This paper reviews the ability of laccase to decolourize dyes in different industries.
\end{abstract}

Keywords - Laccase, Decolourization, White rot fungus, Waste water treatment, Lignin

\section{INTRODUCTION}

Synthetic dyes are broadly used in textile dyeing, paper printing, color photography, pharmaceutical, food, leather industries and cosmetics. Annual production of synthetic dyes has exceeded over $7 \times 10^{5}$ metric tons [1]. Synthetic dyes used are toxic, mutagenic and carcinogenic. Most of the dyes are complex aromatic structure allows for their resistance to light and water oxidation and biodegradation, which is the feature desired by industry using the dye, but it is dangerous for the environment. Coloured waste water is mainly eliminated by physical and chemical processes such as coagulation, flocculation, adsorption, precipitation and membrane separation. However they are very expensive and have drawbacks [2], such as low efficiency, limited versatility, interference by other waste water constituents and handling of the waste generated. Microbial decolourisation is a cost effective process which is receiving much attention for the treatment of dye-containing waste water [3].

Fungi could be an excellent candidate for dye removal [2], can exploit marginal living conditions in large part because they produce unusual enzymes capable of performing chemically difficult reactions [4], and also possess the following advantages over single cell organisms: solubilization of the insoluble substrate and tolerance for high concentrations of the toxicants, as well as greater physical and enzymatic contact with environment because of an increased cell to surface ratio. [3].

Laccase belongs to a group of copper-containing polyphenol oxidases that can catalyze the four-electron reduction of $\mathrm{O}_{2}$ to $\mathrm{H}_{2} \mathrm{O}$ coupled with the oxidation of phenolic compounds. As a ligninolytic enzyme produced by white-rot fungi, laccase exhibits a broad substrate specificity and unique ability of biodegradation [5]. Laccases can be used for the treatment of effluents from pulp mills or from other industries containing chlorolignins or phenolic compounds.

The main objective of this paper is to summarize the means of information available in literature with regard to laccase isolation, identification and mechanism and its role in the decolourisation of different industrial effluents. The present review, therefore should help to elucidate the mechanism of laccase in dye decolourization. 


\section{SOURCES OF LACCASE}

Yoshida in 1883 first described laccase when he extracted it from the Japanese lacquer tree, Rhusvemicifera vermicifera. Laccase was demonstrated to be present in fungi for the first time in 1896 by both Bertrand and laborde. Laccase are widely distributed in higher plants, bacteria, fungi and insects [6,7] which are described as follows:

Plant: Lacquer, peach, mung bean, mango, cabbages, turnips, beets, apples, asparagus, potato and various other vegetables has been detected for the presence of laccase enzyme.

Fungi: Fungal laccases have higher redox potential than bacterial or plant. Fungi from deuteromycetes, ascomycetes as well as basidiomycetes are the good producers of laccase.

Bacteria: Bacterial laccase was first reported in Azospirillum lipoferum [8]. Nowadays laccase is found in many bacteria including Bacillus subtilis, Bordetella compestris, Escherichia coli, Pseudomonas syringae.

Insects: Different insects have also been reported for the production of laccase. Some of them are Bombyx, Calliphora, Diploptera.

\section{ISOLATION OF LACCASE}

Laccases are glycosylated proteins and have been isolated and purified from fungi, bacteria, plant, insects and lichens. The variety of commercial and industrial application of laccases has attracted much attention towards the research addressing different aspects of the protein characterization, production and fit for purpose molecule [9].

Laccases can be isolated from soil samples and tree bark scrapings by employing standard serial dilution method. They can be screened based on the growth on potato dextrose agar media containing specific substrate which included ABTS (2,2'-azino-bis(3-ethylbenzothiazoline-6-sulphonic acid)), guaiacol, tannic acid, syringaldehyde [10].

\section{PURIFICATION OF LACCASE}

Ammonium sulphate is being commonly used for the enzyme purification for many years. Recently researchers have found much more efficient methodologies such protein precipitation by ammonium sulphate, anion exchange chromatography, desalt/buffer exchange of protein and gel filtration chromatography. Previously a lignolytic MnP from Phanerochaete $s p$ was salted out at $65 \%(\mathrm{NH} 4) 2 \mathrm{SO} 4$ saturation with 2.68 -fold purification and $5.56 \%$ yield. The purification step for laccase from Schyzophylum commune are given in Table 1 [11]. A single peak obtained in gel filtration profile (figure:1) showed that laccase had a single enzyme activity and there was no isozyme of laccase [11].

\begin{tabular}{|c|c|c|c|c|c|c|c|}
\hline $\begin{array}{c}\text { Sr. } \\
\text { No }\end{array}$ & Purification steps & $\begin{array}{c}\text { Total } \\
\text { volume } \\
(\mathbf{m L})\end{array}$ & $\begin{array}{c}\text { Total } \\
\text { enzyme } \\
\text { activity (U) }\end{array}$ & $\begin{array}{c}\text { Total } \\
\text { protein } \\
\text { content } \\
\text { (mg) }\end{array}$ & $\begin{array}{c}\text { Specific } \\
\text { activity } \\
\text { (U/mg) }\end{array}$ & Yield (\%) & $\begin{array}{c}\text { Purification } \\
\text { (fold) }\end{array}$ \\
\hline 1 & Crude laccase & 500 & 183500 & 4535 & 40 & 100 & 1 \\
\hline 2 & (NH4)2SO4 ppt & 40 & 88750 & 855 & 104 & 48 & 2.6 \\
\hline 3 & Dialysis & 40 & 79166 & 718 & 110 & 43 & 2.75 \\
\hline 4 & Sephadex G100 & 12 & 6031 & 38 & 158 & 3 & 3.95 \\
\hline
\end{tabular}

Table 1. Purification summary of laccase from Schyzophylum commune IBL-06 


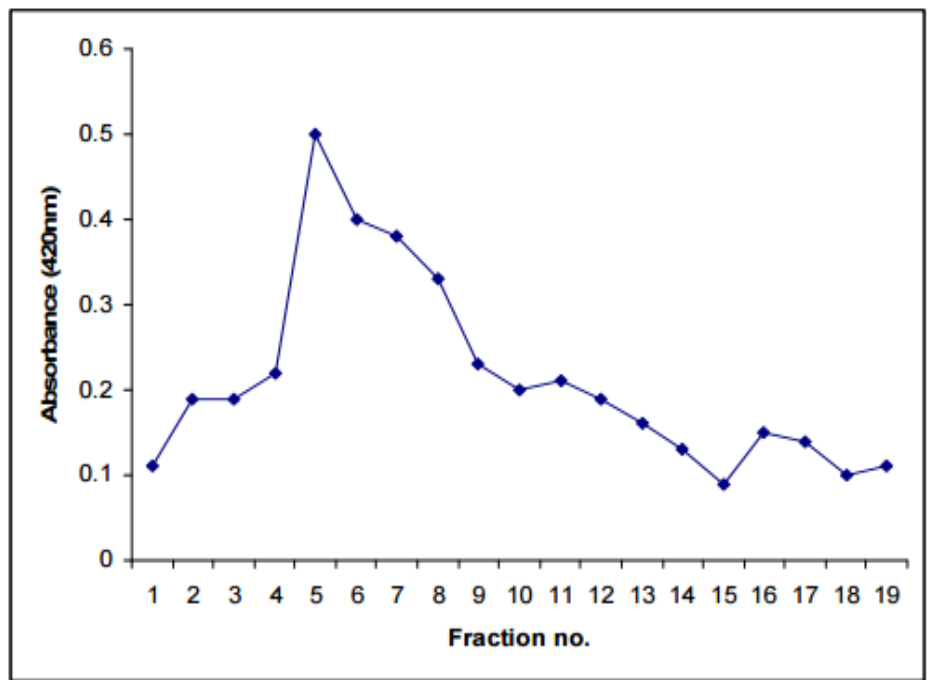

Figure 1. Gel filtration chromatography of laccase produced by Schyzophylum commune IBL-06

\section{MECHANISM OF LACCASES}

The catalysis of laccase occurs with reduction of one molecule of oxygen to water accompanied with the oxidation of one electron with wide range of aromatic compounds which include polyphenols, aromatic amines, methoxy-substituted monophenols (figure 2). This oxidation results in generation of oxygen centered free radicals that can converted to quinone in a second enzyme catalysed reaction. Laccase catalysis occurs in three steps: (1) type I $\mathrm{Cu}$ reduction by substrate; (2) electron transport from type I $\mathrm{Cu}$ to type II $\mathrm{Cu}$ and type III $\mathrm{Cu}$ trinuclear cluster. These three types can be distinguished by using visible electronic paramagnetic resonance (EPR) spectroscopy. Type I Cu give blue colour to protein at absorbance of $610 \mathrm{~nm}$ which is EPR detectable. Type II Cu doesn't give colour which is EPR detectable. Type III $\mathrm{Cu}$ gives weak absorbance in near UV region but not detected by EPR signal [12].
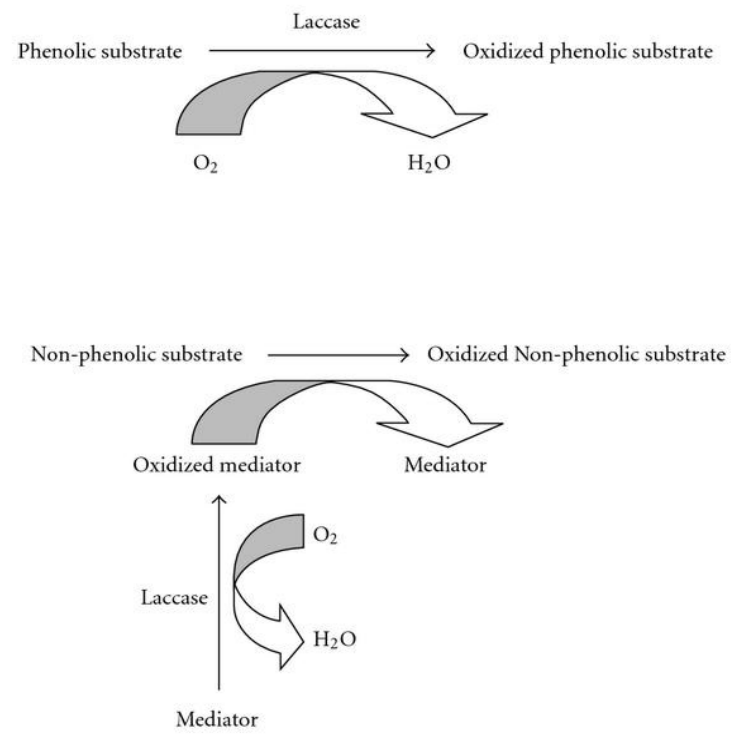

Figure 2. Mechanism of laccase action for both phenolic and non-phenolic substrate 


\section{TYPES OF CULTIVATION}

Enzyme production is a high-ranking field of biotechnology. Most enzyme manufacturers produce enzyme by submerged fermentation (SMF) techniques. Over the past decades there has been an increasing drift towards the use of solid state fermentation technique [13]. However laccases have been produced intensely in both submerged and solid state modes of fermentation. Wild type filamentous fungi are used for large scale production of laccase in different cultivation techniques. Table: 2 list the different cultivation techniques that have been adopted for largescale production of laccase using wild-type filamentous fungi [12].

\begin{tabular}{lllc}
\hline Fungi & Type of cultivation & Inducer & Laccase Activity (U/L) \\
\hline Pycnoporus cinnabarinus & Submerged & $10 \mathrm{mM} \mathrm{Veratryl} \mathrm{alcohol} \mathrm{(VA)}$ & 280 \\
Trametes pubescens & Submerged & $2 \mathrm{~m} \mathrm{Cu}^{2+}$ & 333,000 \\
Neurospora crassa & Submerged & $1 \mu \mathrm{M} \mathrm{cyclohexamide}$ & 10,000 \\
$T$. versicolor & SSF (Immersion, nylon sponge) & Tween 80 & 229 \\
$T$. versicolor & SSF (Immersion, barley bran) & Tween 80 & 600 \\
$T$. versicolor & SSF (Expanded bed, nylon sponge) & Tween 80 & 126 \\
$T$. versicolor & SSF (Expanded bed, barley bran & Tween 80 & 600 \\
$T$. versicolor & SSF (Tray, nylon sponge) & Tween 80 & 343 \\
$T$. versicolor & SSF (Tray, barley bran) & Tween 80 & 3500 \\
T. hirsuta & SSF (Tray, grape seeds) & - & 18,715 \\
\hline
\end{tabular}

Table 2: Production of laccase in different cultivation modes

\section{DYE DECOLOURISATION}

More than 10000 various dyes stable to light, chemicals and microbial degradation are manufactured and used by textile, cosmetic, plastic and printing industries. Based on the chemical structure of chromogenic groups, dyes are classified as azo, heterocyclic/polymeric or triphenyl methanes and about $60 \%$ of produced dyes belongs to the azo groups which are categorized as mono-azo, diazo and triazo dyes [14]. Small scale industries in India contribute 3900 million litres waste water per day. Presence of very low concentrations of dyes in effluents is highly visible and undesirable [15]. Furthermore they damage the esthetic nature of water and reduce light penetration through the water's surface and the photosynthetic activity of aquatic lives. Decolourisation by conventional waste water treatment is inefficient since they are costly, time consuming and often methodologically demanding.

At present a number of studies are focused on white rot fungi which have the capability to degrade various xenobiotic compounds including dyes since they produce some extracellular lignolytic enzymes such as lignin peroxidase, manganese peroxidase and laccase. Laccase have been received a great attention due to their efficiency and low cost of degradation of the organic pollutants including synthetic dyes [16].

Recent research found that laccase of Paraconiothyrium variabile was the most efficient enzyme with $72.2 \%$ removal of bromophenol blue [16]. It was found that this can be achieved after 30 minute treatment in absence of hydroxybezotriazole (HBT). However, decolourisation using laccase of Aspergillus oryzae and Trametes versicolor did not increase higher than $25.3 \%$ even after 3 hours incubation. Compare to laccases from Trametes versicolor and Aspergillus oryzae which represented $30.3 \%$ and $13.3 \%$ decolourisation of comassie brilliant blue [14].

Research by Vaidyanathan et al. [16] shows that the individual dye structures influence the decolourisation extent obtained by laccase, indicating the specificity of laccase towards different dye structures. This reveals the high potential of laccase from Pleurotus ostreatus for dye decolourisation.

Darshan and Kirti studied on decolourisation of reactive orange 16 by Comamonas acidovorans shows that physico chemical parameters such as temperature, $\mathrm{pH}$, culture condition, co-substrate, nitrogen source, salt concentration and metal ions has significant influence on dye removal efficiency. Isolate has shown maximum decolourization at $37^{\circ} \mathrm{C}, \mathrm{pH} 6.85$ using lactose best electron donor and yeast extract as nitrogen source [17].

The purified laccase of Paraconiothyrium variabile studied for its capacity in the removal of aromatic compounds was immobilized on porous silica beads and applied for decolourization of two synthetic dyes of acid blue 25 and acid orange 7 and was found that $\mathrm{pH}$ and thermal stability of immobilized enzyme was improved compared to free laccase, both applied dyes were efficiently decolourised using immobilized laccase [18]. 
A work on decolourisation of an azo dye in an aqueous solution by ozonation in a semi batch bubble column reactor were evaluated and found to be an efficient technique for waste water treatment. The colour removal efficiency of over $98 \%$ was obtained at contact time of $30 \mathrm{~min}$, which proved that ozonization is a very efficient process for colour removal [19].

Robert Mass et al studied the decolourisation of azo dye RR2 in semi continuous anaerobic reactors and found that after an initial adsorption of dye on the biomass subsequent degradation of dye occurred which suggest that the primary mechanism of dye removal appears to be adsorption of dye on biomass followed by biodegradation [20]. White rot fungi were capable of secreting active ligninolytic enzymes and decolourising the pulp and paper mill waste water. On direct addition of glucose to the waste water source, it has been found to be more economical to reduce or substantially remove color from the waste water by additionally adding white rot fungi in the presence of cellulose and hemicellulose [21].

Decolorization of pulp and paper mill effluent by lignin-degrading fungus Aspergillus flavus strain F10 indicate that the utilization of Aspergillus flavus F10 is suitable for the decolorization and polyphenolic groups removal from soda pulping effluents in the presence of a carbon source and the toxicity of the treated effluent was found to be reduced [22].

Poonam Dayaram et al observed that the ready availability of laccase from Polyporous rubidus and its robust characteristics help to overcome the barriers for waste water treatment. Their results suggested that laccase from Polyporous rubidus could decolourise synthetic dyes in broad range of concentration without the need for redox mediators, provided that the dyes are water-soluble. Also found out that immobilized enzymes tend to have higher activity and are more resilient to environmental perturbations such as $\mathrm{pH}$ or exposure to toxic chemical concentration than suspension cultures. The enzyme from Polyporous rubidus was also found to be effective in removing colour from untreated effluents. Through this study they showed that white rot fungi, Polyporous rubidus is far more efficient for decolorizing a range of industrially important textile dyes and real waste water from industries [23].

\section{CONCLUSION}

Colour is all around us. Wherever we look we see colours, even if we do not always notice them. Nowadays the human activities are disturbing these colours by disposing synthetic colour in nature. Synthetic dyes are broadly used in textile dyeing, paper printing, color photography, pharmaceutical, food, leather industries and cosmetics. Most of these industries dispose their effluent without any treatment technologies. Dyes are the most difficult constituents to remove by conventional waste water treatment, and are mainly removed by physical and chemical methods, which are expensive. Hence the biological processes become the most prominent technology for dye decolourisation. Fungi could be an excellent candidate for dye removal. Laccases are muticopper oxidases, found in many plants, fungi and microorganisms. It was found that laccase plays a crucial role in the formation of lignin by promoting the oxidative coupling of monolignols, a family of naturally occurring phenols. Both water consumption and effluent toxicity in dyeing industries could be reduced by enzyme remediation with laccases. Hence laccase is receiving much attention of researchers around the globe.

\section{REFERENCES}

[1] Singh, Sreenath, "Microbial degradation of synthetic dyes in waste water", Lucknow, Uttar Pradesh, Springer, 2014.

[2] Wioletta Przystas, Ewa Zablocka-Godlewska, Elzbieta Grabinska-Sota, "Efficacy of fungal decolorisation of a mixture of dyes belonging to different classes", Brazilian Journal of Microbiology. 2015;46(2):415-424

[3] Chang-en Tian, Ruical Tian, Yuping Zhou, Qionghua Chen, Huizhen Cheng, "Decolorisation of indigo dye and indigo dye containing textile effluent by Ganoderma weberianum", African Journal of Microbiology Research. 2013;7(11):941-947

[4] Buddolla Vishwanath, Bandi Rajesh, Avilala Janardhan, Arthala Praveen Kumar, Golla Narasimha, "Fungal laccases and their application in bioremediation", Dynamic Biochemistry, Process Biotechnology and Molecular Biology. 2008;2(1):1-13

[5] Yang Yang, Fuxiang Wei, Rui Zhuo, Fangfang Fan, Huahua Liu, Chen Zang, Li Ma, Mulan Jiang, Xiaoyu Zang, “ Enhancing the laccase production and laccase gene expression in the white rot fungus Trametes velutina 5930 with great potential for biotechnological applications by different metal ions and aromatic compounds", Plos one. 2013;8(11):1-18

[6] Kuntal Kalra, Rohit Chauhan, Mohd. Shavez, Sarita Sachdeva, "Isolation of laccase producing Tricoderma Spp. and effect of pH and temperature on its activity", International Journal of Chemtech Research. 2013;5(5):2229-2235

[7] D Faure, M L Bouillant, R Bally, "Isolation of Azospirillum lipuferum 4T Tn5 mutants affected in melanization and laccase activity", Applied and Environmental Microbiology. 1994;60(9)3413-3415

[8] Syed Faraz Moin, Muhammed Nor Bin Omar, "Laccase enzymes: purification, structure to catalysis and tailoring", Protein and Peptide Letters. 2014;21(8):707-713 
[9] Savitha S Desai, Gururaj B Tennali, Nithyanad Channur, A C Anup, Gouri Deshpande, B P Azhar Murtuza, "Isolation of laccase producing fungi and partial characterization of laccase", Journal of Biotechnology, Bioinformatics and Bioengineering. 2011;1(4):543-549

[10] G Roseline Jebapriya, J Joel Gnanadoss, "Screening and molecular characteristaion of white rot fungi capable of laccase production and dye decolorisation", International Journal of Life science and Pharma Research. 2014;4(2):12-20

[11] Khushal Brijwani, Anne Rigdon, Praveen V Vadlani, "Fungal laccases: production, function and applications in food processing”, Journal of Enzyme research. 2010;10:1-10

[12] J L Toca-Herrera, J F Osma, S Rodriguez Couto, "Potential of solid-state fermentation for laccase production", Communicating Current Research and Educational Topics and Trends in Applied Microbiology. 2007;391-400

[13] Hamid Forootanfar, Atefeh Moezzi, Marzieh Aghaie-Khozani, Yasaman Mahmoudlanlou, Alieh Ameri, Farhad Niknejad, Mohammad Ali Faramarzi, "Synthetic dye decolourization by three sources of fungal laccase", Journal of Environmental Health Science and Engineering. 2012;9(27):1-8

[14] Prachi Kaushik, Anushree Malik, "Microbial decolourisation of textile dyes through isolates obtained from contaminated sites", Journal of Scientific and Industrial Research. 2009;68:325-331

[15] Karnika Ratanapongleka, Jirapa Phetsom, "Decolourization of synthetic dyes by crude laccase from Lentinus Polychrous Lev",International Journal of Chemical Engineering and Applications. 2014;5(1):26-30

[16] Vaidyanathan Vinoth Kumar, Selvaraj Dinesh Kirupha, Premkumar Periyaraman, Subramanian, "Screening and induction of laccase activity in fungal species and its application in dye decolourization", Applied Journal of Microbiology Research. 2011;5(11):1261-1267

[17] Darshan M. Rudakiya, Kirti S. Pawar, "Optimization of culture condition for enhanced decolorization of Reactive Orange 16 by Comamonas acidovorans MTCC 3364”, International Journal of Current Microbiology and Applied Sciences. 2013;2(10):467-476

[18] Seyedeh-Shaghayegh Mirzadeh, Seyed-Mostafa Khezri, Mohammad Ali Faramarzi, "Decolourization of two synthetic dyes using the purified laccase of Paraconiothyrium variabile immobilized on porous silica beads", Journal of Environmental Health Science and Engineering. 2014;12(6):1-19

[19] Che Zulzikrami Azner Abidin, Muhammad Ridwan Fahmi, Ong Soon-An, Siti Nurfatin Nadhirah Mohd Makhtar, Nazzery Rosmady Rahmat, "Decolourization of an azo dye in aqueous solution by ozonation in a semi batch bubble column reactor", Science Asia. 2015;41:49-54

[20] Robert Maas, Sanjeev Chaudhari, "Adsorption and biological decolourisation of azo dye Reactive Red 2 in semi continuous anaerobic $\begin{array}{lll}\text { reactor", } & \text { Process } & \text { Biochemistry. }\end{array}$

[21] Gomathy V Cibichakravarthy, B Ramanathan, A Sivaramaiah Nallapeta, Ramanjaneya V, R Malu, Jayasimha Rayalu, "Decolourisation of paper mill effluent by immobilized cells of Phanerochaete chrysosporium", International Journal of Plant, Animal and Environmental Sciences. 2012;2(1):141-146

[22] Anand Barapatre, Harit Jha, "Decolourisation and biological treatment of pulp and paprer mill effluent by lignin-degrading fungus Aspergillus flavus strain F10", International Journal of Current Microbiology and Applied Sciences. 2016;5(5):19-32

[23] Mohamed N Bayoumi, Raed S Al-Wasify, Shimaa R Hamed, "Bioremediation of textile waste water dyes using local bacterial isolates", International Journal of Current Microbiology and Applied Sciences. 2014;3(12):962-970 